\title{
CONSTRUCTION INDUSTRIALIZATION AND IT INTEGRATION: HOW TALL WOOD BUILDINGS CAN SHOW THE RIGHT PATH TOWARDS CONSTRUCTION 4.0
}

\author{
Conrad Boton* and Daniel Forgues* \\ * École de Technologie Supérieure, Dept. of Construction Engineering, Canada \\ e-mails: conrad.boton@etsmtl.ca, daniel.forgues@etsmtl.ca
}

\begin{abstract}
The construction industry has been considered as refractory to information technologies. However, new technological approaches, such as the Building Information Modeling (BIM), are becoming increasingly adopted and are promising better collaboration, better flow optimization and greater integration of the supply chain. These changes are preparing the industry for the advent of "Construction 4.0", a more federating concept than BIM. This article explores the concept and shows how tall wood buildings could show the right path and lead the way for the rest of the industry. The research shows that while tall wood construction actually presents the potential to fit the construction 4.0 requirements, current practices are far from being uniform from one project to another. It also illustrates the need for a close collaboration between practitioners and researchers in order to overcome the current challenges.
\end{abstract}

Keywords: Construction 4.0, Tall wood buildings, Building Information Modeling, IT integration.

\section{INTRODUCTION}

The construction industry is lagging far behind other industries such as aerospace and the automotive industry in terms of information technologies integration [1]. For a long time, it has failed to put in place integrated and efficient practices based on information and communication technologies. It is therefore crucial to not miss the digital transition initiated by the development of the Building Information Modeling (BIM) approach. A recent report concluded that the construction industry has no choice but to move towards such a transformation, including on construction sites [2]. Based on the German case, the same report shows that $93 \%$ of construction industry stakeholders agree that such a digital shift should affect all processes, the importance of understanding the digital shift in the construction industry in order to better accompany it and provide the best answers. It must be said that the Building Information Modeling (BIM) approach is dramatically changing the way projects are managed in architecture, engineering and construction [3]. The BIM approach's recent technological developments are full of promises. By providing a three-dimensional model as a central component of construction projects, BIM gives the construction industry the tools it needs to better manage its duality of process and product. The model of the product can, therefore, be more finely analysed upstream in order to both open up the design process and fine-tune the construction [4].

But the recent developments of "industry 4.0" in the manufacture [5], a concept based notably on the digitization and integration of vertical and horizontal value chains and the development of new digital business models and platforms [5], lead one to wonder about the reducing nature of the BIM concept as currently developed in the construction and to imagine the idea of a more encompassing and unifying concept. This article explores the concept of "Industry 4.0" and shows how tall wood buildings could show the right path and lead the way for the rest of the industry. It is organized in 3 main parts. The first part presents a review of the literature on the specificities of the construction industry and the challenges it faces. The concept of "construction 4.0" is then developed in order to highlight the main characteristics 
that differentiate it from BIM and industry 4.0. The third part uses three Canadian tall wood case studies to illustrate and evaluate these characteristics.

\section{CONSTRUCTION 4.0: TOWARDS A NEW FEDERATING CONCEPT POST-BIM}

\subsection{Why Construction 4.0?}

The development of the BIM approach, a major unifying concept, has been very important in raising awareness and progressive paradigm shift in the construction industry. the transition to "Construction 4.0" seems increasingly necessary in order to enabling industry to move beyond the limits of the BIM approach as currently developed. Indeed, it appears more and more necessary to find a theoretical concept able to federate not only the BIM-related issues but also the new approaches coming from other discrete manufacture industries and aiming at improving collaboration and productivity in construction.

Many interesting and relevant theoretical approaches have been proposed in the literature to improve productivity in construction but are related to specific aspects of construction. One of the most known modern theoretic approaches in construction production is the TFV production theory [6]. It considers three important views for production management: Transformation view, Flow view and Value generation view [6]. The transformation view decomposes the total transformation (of inputs to outputs) into elementary tasks in order to carry out the tasks as efficiently as possible. The flow view considers production as a flow which encompasses with the transformation, some moving and inspection stages. According to the value generation view, the production aims at ensuring that the product designed corresponds to the customer needs. These three complementary views co-exist, so managing production equals to managing tasks, flow, and value. In practice, Bertelsen and Koskela [6] proposed to focus on three main management functions: contract management (contract, claims, success criteria, etc.), process management (production flow, cooperation, planning methods, etc.) and value management (customer satisfaction, process related value, etc.). Another concept comes from the systemic approach recently proposed to study collaboration in the construction industry [4]. It uses a systemic triangulation according to different levels of study (industry, project, firm and activity levels) in order to derivate the main relevant components to consider in the study of the construction industry as a complex system [4].

While the first step of the paradigm shift of the construction industry towards better productivity and sustainability corresponds to the development of the BIM approach, a major unifying concept, is very important in the required paradigm shift in the industry, the transition to "Construction 4.0", defined as the "post-BIM" major unifying concept, is crucial to enable the industry to take full advantage of the various advances in information technology, while creating the environment necessary for better productivity and more sustainable buildings in terms of energy and materials consumption. In this perspective, "Construction 4.0" as new unifying concept should not be just an instantiation of "Industry 4.0 " in construction, but an innovative concept taking into account these challenges. Thus, it should be located at the intersection of three major issues: digital shift, industrialization of construction, and sustainable construction (see Figure 1). The digital shift is related not only to the use of BIM technologies, but also other complementary technologies including the Internet of Things (IoT), cloud computing, Big Data, 3D printing, smart sensors, augmented reality, mobile technologies, etc. The industrialization of construction aims at finding ways and means to reduce waste in construction supply chain and to improve efficiency on construction sites in order to increase productivity in the industry. This includes, but is not limited to, Lean Construction, Last Planner, multidisciplinary prefabrication, offsite construction, etc. The sustainable aspect of construction is related to the three pillars of sustainable development, including economic, ecological and social challenges. 


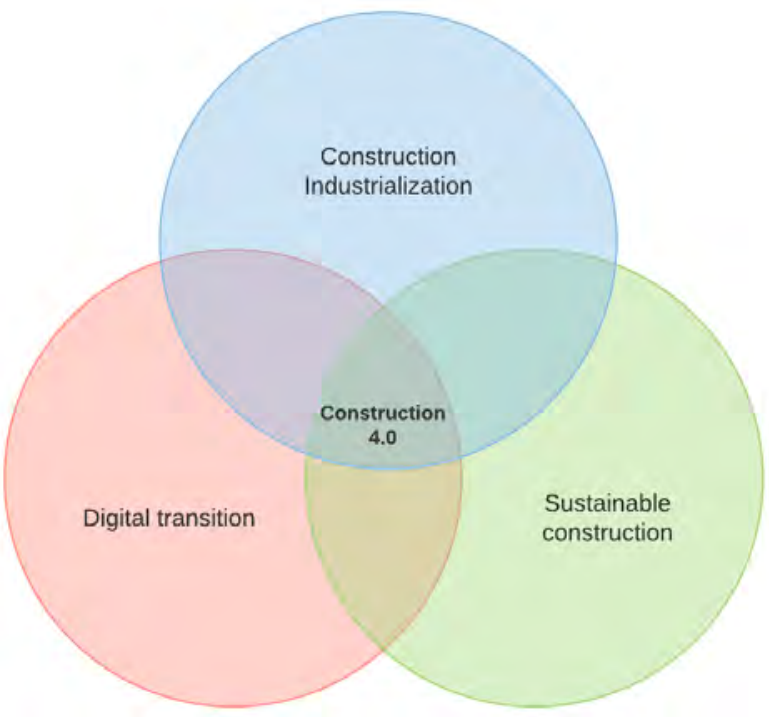

Figure 1. The three major challenges of Construction 4.0

\subsection{How tall wood buildings can show the right path}

Although the traditional concrete and steel construction struggled to integrate the 3 aspects of Construction 4.0 concepts mentioned in Figure 1, the wood construction has, with tall wood buildings, interesting characteristics that enable it to position itself as a leader in this field. Indeed, it offers considerable advantages in terms of sustainable construction, prefabrication and industrialization, but also potential in integrating information technologies since recent experiences reported [7] point to a very favorable context for the use of information and communication technologies.

The design of tall wood buildings requires a much broader perspective in which designers must take into account "the integration of all building systems, the building envelope, and performance detailing, as well as architectural form, function, and flexibility from the outset of the design process" [8]. This encourages project teams to use innovative approaches such as the Integrated Design Process (IDP) and simulation tools such as those proposed in the BIM approach. The goal is to study, through real-time simulation, the impacts of different technical alternatives on the behaviour of the building and its constructability. Thus the construction simulation and information integration tools find a particularly fertile ground.

In addition, tall wood constructions involve extensive use of prefabrication and rapid component assembly processes [9], [10] to guarantee a better cost competitiveness. Such a degree of use of prefabrication, which is still low in traditional concrete and steel constructions, makes it possible to take better advantage of good practices coming from more productive industries, such as aerospace and automotive. Thus, Design for Manufacture and Assembly (DfMA) can reasonably be introduced more easily in tall wood buildings. The general principle is to enable the building components to be manufactured in a factory environment in order to considerably reduce on-site activities [11]. This includes the design rationalization, the materials use optimization, the use of just-in-time delivery, and logistics planning in order to significantly increase productivity rates on the construction site [11]. Prefabrication can greatly contribute to the quality of the works and to the reduction of delays, but this requires that particular attention be paid to the availability of adequate storage areas, detailed study of steel wood connections, use of prefabricated elements, architectural requirements or engineering details, 
and construction details [8]. It should be noted that according to the RIBA Plan Of Work [11], adopting DfMA does not necessarily mean adopting manufactured or standard elements.

Regarding the sustainable construction, the Technical Guide for the Design and Construction of Tall Wood Buildings in Canada [8] notes that "when compared to steel and concrete structural systems, tall wood building systems offer a number of important environmental advantages" (Figure 2). These advantages include sustainable and renewable resources utilization, energy carbon, and waste footprints reduction, the energy consumption reduction, etc.

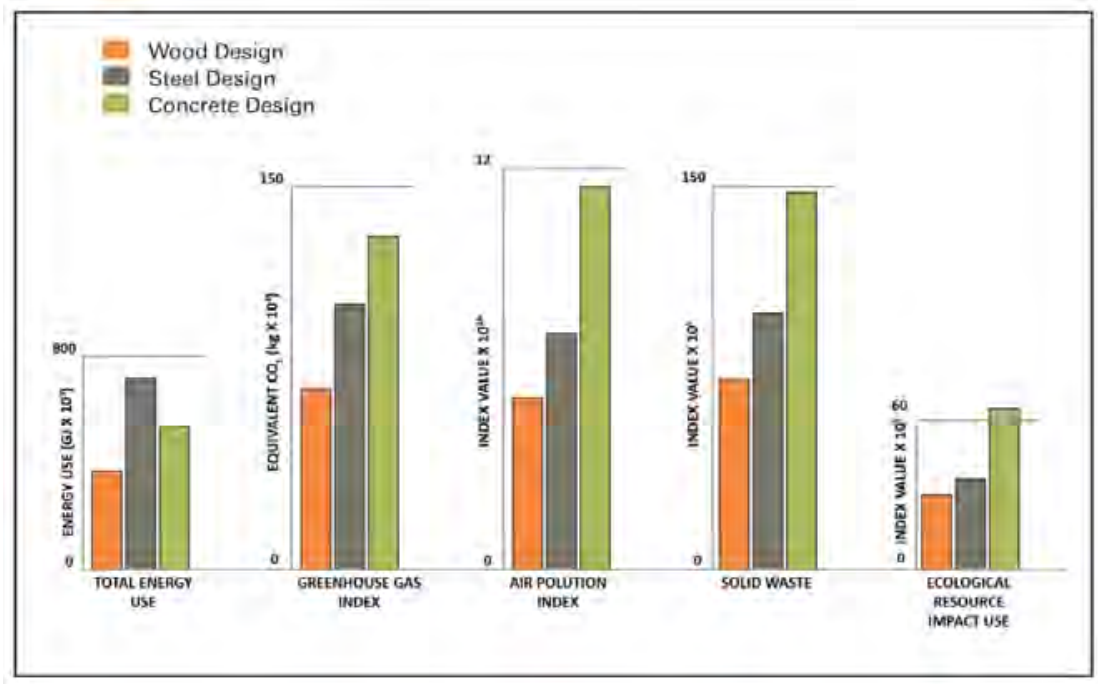

Figure 2: Environmental impact of different structural typologies [8]

\section{CASE STUDY}

\subsection{The research approach}

Our study is based on a mixed approach that combines the collection of quantitative and qualitative data. Three projects representing 3 different tall wood bulding contexts in Canada were selected. Semistructured interviews were then conducted to better understand the context of the projects, and the innovative processes, tools and organizations used. A first round of interviews and data collection was conducted between September 2016 and March 2017. A preliminary report was produced and presented to the managers of the different projects, as basis to discuss and evaluate the main challenged they had to face during the project.

The 3 selected tall wood buildings are located in Canada. They are in progress and illustrate the willingness of the client to take part in the turning point of innovation initiated by the reintroduction of timber construction for multi-residential buildings and the use of the prefabrication process associated with the new technologies for their realization. The first project is a tall wood project composed of 92 units of condominiums. This tower is located in Quebec City. With thirteen floors and about 40 meters high, the project is designed to be one of the highest solid wood towers in the world. The second project is a multi-residential building located in the heart of Montreal. It develops on three 8-level buildings that occupy a triangular block. 464 dwellings are located in three buildings that border an island core converted into an interior garden, occupied by a swimming pool for the residents. The third project is one of the tallest wood building projects in the world. It is located in Vancouver in Canada. The reduced size 
of the plot available under the program has oriented the architectural solution towards a typology of a tower, likely to contain sleeping spaces (shared rooms) and common spaces for public facilities.

The projects are studied according to different criterion related to the context (main characteristics, the reasons for choosing wood, the financial aspects, the legal context), the processes (the selection of professionals, the design framework, the use of Integrated Design Process, the used of Building Information Modeling, the 3D-based coordination and management), and the local industry readiness), and the buildings themselves (Main innovations, productivity rates, etc.).

\subsection{Lessons learned}

\subsubsection{Regarding the context of the projects}

The context had a major impact on the innovative character of the project. The Project 3 stands out from the other two projects for several reasons. First, it is a project of a public university that sets itself apart from other clients on two points: its commitment to sustainable construction, with a campus whose recent projects make remarkable use of wood as building material; its philosophy of making its construction projects into research laboratories in which its researchers are invited to become actively involved. Second, wood is a preferred material for architects in British Columbia and for professionals and builders who are somewhat more seasoned in the use of wood for buildings and the use of CLT panels, even though Quebec is more to the level of regulation. Also, unlike in Quebec, the practice of integrated design is very widespread among professionals. Third, three major constraints have forced the search for innovative solutions: a very tight schedule, a particularly constraining site for a building of this height and a climate with a need to avoid conditions created by heavy rains. These constraints have had a significant influence on the process, requiring an intensive collaborative approach supported by BIM and PLM technologies and the advanced use of prefabrication.

Québec's projects have evolved in a less favourable context with regard to the maturity of the workforce, the training and expertise of professionals with wood and with information technology, the preparation and understanding of fire safety issues and support for university research. Also, they did not have generous subsidies. It could be argued that the Project 3 and Project 1 projects benefited from subsidies that somewhat distorted the competitiveness of the wood solution on the market. However, the Owner of Project 2 has demonstrated with its project that this constructive choice can be advantageous, even under difficult conditions (decontamination, accessibility costs in a high density environment) and a highly competitive adjacent market (significant offer of new condominiums in the neighbourhood). Another interesting point highlighted for Quebec projects is the maturity of the market. For both projects, potential buyers have demonstrated a surprising knowledge about constructive choice and this choice represented an added value, not only in terms of a citizen's choice for sustainable development, but also for the superior construction quality prefabrication. "At first it was thought that there should be a lot to explain on the value of wood. What we realized over time was that it was not a handicap, but people had knowledge of the wood, did a lot of research on it and were excited about it. It is even an element that fosters sales," said an official of the Project 1.

\subsubsection{Regarding the processes}

For the design process, the three projects used integrated teams, more or less according to the Integrated Design Process principles. The consortium of Project 1 conducted the design process as a continuous integrated design. "We did not have a project office named as such, but there were weekly design meetings," says a project manager. "It is an integrated design process with design "charrettes" and a coordination done with structure, mechanics and general contractor. Everything is done together, in collaboration" he said. "It was a really very close design," confirms another official. "We made a lot of iterations between structure and architecture; we had the chance to be able to work very close like that. The architect was thus able to optimize the frames to favor the wooden structure ".

For the Project 2, the developer chose to distinguish himself by his concern for innovation and sustainable construction. The team has been trained in integrated design process and its particular use was 
distinguished by a continuous improvement approach in which the lessons learned are quickly integrated into the successive phases of the project. So if phases 1 and 2 were not realized $100 \%$ in integrated design because "it is a concept that was not mastered by the project team and especially the architects" according to a project manager. But "seeing that it's interesting, we asked our architects and they were trained for that purpose," he continues. "From the moment they have acquired this vision, all the projects that can be done are done in integrated design process". Thus, "phase 3 will be done entirely in integrated design [...]. It's much more profitable to do it that way than traditionally" he concludes.

The Project 3 is distinguished primarily by the support of university research for the development of innovative design practices and access to higher-level professional resources. The architect responsible for design is one of the pioneers in integrated design and sustainable construction in Canada, with a large research and development team that collaborates with several universities. The client also hired a BIM / PLM integrator, which uses 3D Experience, a PLM platform developed by Dassault Systems. Finally, the entire process was monitored by the university dedicated research group team, which helped optimize the entire process while collecting data in real time in order to capture, formalize and share the new practical knowledge. The main benefits of these distinctive elements have been important advances in both the design and construction processes. For design, the BIM / PLM integrator modified design models in real time to explore the different options and conduct the simulations in order to compare the different options. The manufacturer and the main subcontractors were also involved in validating the proposed solutions. This design approach had a significant impact on the construction: 1) BIM / PLM integrator applied sequencing optimization techniques to the assembly, allowing for the application of the Just-in- Time principles (there were no storage or movement of the panels on the site, the cycle of arrival of the trucks was timed to that of the assembly), 2) the very high level of prefabrication which included the envelope as well as the elements of plumbing, 3) the speed of assembly thanks to the optimization of the components for the assembly.

\subsubsection{Regarding the buildings}

Wood panels and structural elements came from the same manufacturer in Quebec and another one in British Columbia, which explains few differences in assembly configurations. Concrete for the ground floor and foundations was used in all the three cases. Solutions for the concrete base vary from project to project and have been dictated by the site conditions. For example, a floating caisson was used in Quebec because of poor soil lift and high water table.

The distinctions between constructive choices for wood are found in the choice of wood-wood and steel-wood fasteners. However, the main difference is the adoption of a concrete cage for vertical traffic for Project 3, unlike wood panels for the other two projects. It was mentioned for the Project 1 that the panel would be favoured if it had to be remade, given the complexity caused by the requirements of resistance to fire and others. If it were to be remade, "possibly we would not build the staircases of solid wood again because of the complexity of the assemblies", according to a person in charge of the Project 1.

The prefabrication component was also much more extensive for the Project 3, especially at the envelope level. If for Project 2 the envelope is of traditional construction, for Project 1 the CLT panels were used with the openings realized in factory for the windows and patio doors. In Project 3 , the envelope panels were entirely manufactured in the factory.

\section{CONCLUSION}

While the first step of the paradigm shift of the construction industry towards better productivity and sustainability corresponds to the development of the BIM approach, a major unifying concept, is very important in the required paradigm shift in the industry, the transition to "Construction 4.0", defined as the "post-BIM" major unifying concept, is crucial to enable the industry to take full advantage of the various advances in information technology, while creating the environment necessary for better productivity and more sustainable buildings. Based on three Canadian case studies, this article explored the concept and illustrated how tall wood buildings could show the right path and lead the way for the 
rest of the industry. The research showed that while tall wood construction actually presents the potential to fit the construction 4.0 requirements, current practices are far from being uniform from one project to another. It also showed the need for a close collaboration between practitioners and researchers in order to overcome the current challenges.

Future works will focus on better formalizing the concept and deepening the comparison with other discrete manufacturing industries.

\section{REFERENCES}

[1] C. Boton, L. Rivest, D. Forgues, and J. Jupp, "Comparing PLM and BIM from the Product Structure Standpoint," in Product Lifecycle Management for Digital Transformation of Industries. PLM 2016. IFIP Advances in Information and Communication Technology, 2016, vol. 492, pp. 443-453.

[2] Roland Berger GmbH, "Digitization in the construction industry Building Europe's road to „construction 4.0, “e” pp. 1-16, 2016.

[3] C. Eastman, P. Teicholz, R. Sacks, and K. Liston, BIM Handbook: A Guide to Building Information Modeling for Owners, Managers, Designers, Engineers and Contractors. 2011.

[4] C. Boton and D. Forgues, "The need for a new systemic approach to study collaboration in the construction industry," Procedia Eng., vol. 196, no. June, pp. 1043-1050, 2017.

[5] PwC, "Industry 4.0: Building the digital enterprise - Engineering and construction key findings," pp. 1-36, 2016.

[6] S. Bertelsen and L. Koskela, "Managing the Three Aspects of Production in Construction," in 10th Annual Conference - International Group for Lean Construction (IGLC-10), 2002, pp. 1-9.

[7] J. Bowyer, S. Bratkovich, J. Howe, K. Fernholz, M. Frank, S. Hanessian, H. Groot, and E. Pepke, "Modern Tall Wood Buildings: Opportunities for Innovation," 2016.

[8] FPInnovations, "Technical Guide for the Design and Construction of Tall Wood Buildings in Canada," 2013.

[9] A. Waugh, M. Wells, and M. Lindegar, "Tall Timber Buildings: Application of Solid Timber Constructions in Multi-Storey Buildings," in Proceedings of the International Convention of Society of Wood Science and Technology and United Nations Economic Commission for EuropeTimber Committee, 2010, pp. 1-9.

[10] C. Loss, M. Piazza, and R. Zandonini, "Connections for steel - timber hybrid prefabricated buildings . Part I : Experimental tests,” Constr. Build. Mater., vol. 122, pp. 796-808, 2015.

[11] D. Sinclair, B. Wood, and S. Mccarthy, "RIBA Plan of Work 2013 Designing for Manufacture and Assembly," 2013. 